Article

\title{
Simultaneous detection of hydroxylamine and phenol using $p$-aminophenol-modified carbon nanotube paste electrode
}

\author{
Ali A. Ensafi *, E. Heydari-Bafrooei, B. Rezaei \\ Department of Chemistry, Isfahan University of Technology, Isfahan 84156-83111, Iran
}

A R T I C L E I N F O

Article history:

Received 26 February 2013

Accepted 27 June 2013

Published 20 September 2013

Keywords:

Hydroxylamine and phenol

determination

p-Aminophenol

Multiwall carbon nanotube paste

electrode

Voltammetry

\begin{abstract}
A B S T R A C T
A carbon paste electrode that was chemically modified with multiwall carbon nanotubes and $p$-aminophenol was used as a selective electrochemical sensor for the simultaneous detection of hydroxylamine (HX) and phenol. Cyclic voltammetry, double potential-step chronoamperometry, square wave voltammetry (SWV), and electrochemical impedance spectroscopy were used to investigate the use of $p$-aminophenol in the carbon nanotubes paste matrixes as a mediator for the electrocatalytic oxidation of HX and phenol in aqueous solution. The coefficient of electron transfer and catalytic reaction rate constant were determined using the electrochemical methods. Under optimized conditions, the electrocatalytic oxidation current peaks for HX and phenol increased linearly with concentration in the range of $0.5-180.0$ and $10.0-650.0 \mu \mathrm{mol} / \mathrm{L}$ for $\mathrm{HX}$ and phenol, respectively. The detection limits for HX and phenol were 0.15 and $7.1 \mu \mathrm{mol} / \mathrm{L}$, respectively. The anodic potential peaks of HX and phenol were separated by $0.65 \mathrm{~V}$ in SWV. Because of good selectivity and sensitivity, the present method provides a simple method for the selective detection of HX and phenol in practical samples such as water samples.
\end{abstract}

(C) 2013, Dalian Institute of Chemical Physics, Chinese Academy of Sciences. Published by Elsevier B.V. All rights reserved.

\section{Introduction}

Contamination of fresh water by many chemical compounds and industrial wastes is a key environmental problem facing humanity. Most of these compounds cause considerable toxicological concerns. Assessing the impact of pollutants in aquatic systems requires the development of suitable analytical methods with high selectivity and sensitivity. Hydroxylamine (HX) is a reactive chemical with the formula of $\mathrm{NH}_{2} \mathrm{OH}$, and its derivatives are also reactive when one or more of the hydrogen atoms are replaced by substituents. HX tends to be explosive, and the nature of the hazard is not entirely understood [1]. HX is used as a reducing agent in many organic and inorganic reactions. It can also act as an antioxidant for fatty acids. HX is produced in the reduction of nitrates by E. coli and Torula yeast. It has also been detected in bacterial media and in the tissues of a number of organisms. Ammonia is reported to be produced in vivo from $\mathrm{HX}$ by various microorganisms [1]. HX and its derivatives are more safely handled in the form of salts [2]. Therefore, the determination of HX is important in many environmental and industrial situations. Several methods have been developed for the determination of $\mathrm{HX}$, e.g., chromatographic [3], spectrophotometric [4-6], and electrochemical methods [7-12] have been successfully applied for the determination of HX.

Phenol and its vapors are corrosive and harmful to eyes, skin, and the respiratory tract [13]. Repeated or prolonged skin contact with phenol can cause dermatitis and even second or third degree burns owing to the caustic and defatting properties of phenols [14]. Inhalation of phenol vapor can cause lung edema $[15,16]$. Therefore, the detection of this compound is also very important. Different methods have been proposed for the determination of phenol including high performance liquid

*Corresponding author. Tel: +98-311-3913269; Fax: +98-311-3912350; E-mail: ensafi@cc.iut.ac.ir 
chromatography [17-19], capillary electrophoresis [20], spectrophotometry [21], and electrochemical methods [22-24].

$\mathrm{HX}$ and phenol are two important hazardous compounds that can be found together in water samples. Therefore, the detection of these compounds in the presence of one another is important. The potential peaks of these compounds overlap when unmodified electrodes such as glassy carbon electrode, Pt-electrode, and carbon paste electrode (CPE) are used. Thus, it is impossible to measure the concentrations of these compounds in the presence of one another using voltammetric methods.

The closed topology and tubular structure of multiwall carbon nanotubes (MWCNTs) [25-27] give them interesting chemical and electrochemical properties. A number of investigations [28-32] have been carried out to look at the applications of MWCNTs in electrocatalysis, hydrogen storage, and intercalation. No paper has reported the simultaneous electrocatalytic determination of $\mathrm{HX}$ and phenol using a mediator (electrocatalysis). In this paper, we report the preparation and use of a $p$-aminophenol-modified MWCNT paste electrode ( $p$-APMCNTPE) as a new sensor for the determination of HX and phenol in aqueous solution. We evaluated its analytical performance in the quantification of $\mathrm{HX}$ in the presence of phenol. The method is fast, simple, and sensitive enough to detect and measure these species in practical samples such as wastewater.

\section{Experimental}

\subsection{Chemicals}

All chemicals used were analytical reagent grade purchased from Merck (Darmstadt, Germany) unless otherwise stated. Doubly distilled water was used throughout. $p$-Aminophenol from Fluka and HX and phenol from Merck were used as received.

HX solution $(0.01 \mathrm{~mol} / \mathrm{L})$ was prepared daily by dissolving $0.0640 \mathrm{~g}$ of HX in water, and the solution was diluted to $100 \mathrm{~mL}$ with water in a $100 \mathrm{~mL}$ volumetric flask. The solution was kept in a refrigerator at $4{ }^{\circ} \mathrm{C}$ in the dark. Further dilution was made with water.

Phenol stock solution ( $0.01 \mathrm{~mol} / \mathrm{L})$ was prepared by dissolving phenol $(0.0941 \mathrm{~g})$ in a phosphate buffer solution $(0.1$ mol/L, pH 7.0) in a $100 \mathrm{~mL}$ volumetric flask, and this was ultrasonicated for several minutes. This solution must be prepared fresh daily because it does not keep since phenol is not stable but decomposes slowly in air and light. Further dilution was made with water.

Phosphate buffer solutions (sodium dihydrogen phosphate and disodum monohydrogen phophate plus sodium hydroxide, $0.1 \mathrm{~mol} / \mathrm{L}$ ) with different $\mathrm{pH}$ values were used.

High viscosity paraffin oil $(d=0.88 \mathrm{~kg} / \mathrm{L})$ from Merck was used as the pasting liquid for the preparation of the electrodes. Spectrally pure graphite powder (particle size $<50 \mu \mathrm{m}$ ) from Merck and MWCNTs $(>90 \%, d \times l=(110-70 \mathrm{~nm}) \times(5-9 \mu \mathrm{m}))$ from Fluka were used as the substrate for the preparation of the paste electrodes.

\subsection{Apparatus}

Cyclic voltammetry (CV), chronoamperommetry, electrochemical impedance spectroscopy (EIS), and square wave voltammetry (SWV) were performed in an analytical system using an Autolab PGSTAT 12 potentiostat/galvanostat connected to a three-electrode cell, Metrohm Model 663 VA with Autolab software. The system was run by a PC using GPES and FRA 4.9 software packages. For the impedance measurements, a frequency range of $100 \mathrm{kHz}$ to $1.0 \mathrm{~Hz}$ was employed. An AC voltage amplitude of $5 \mathrm{mV}$ was used, and the equilibrium time was 1 min. A conventional three-electrode cell assembly was used, which consisted of a Pt wire as an auxiliary electrode with a $\mathrm{Ag} / \mathrm{AgCl}\left(\mathrm{KCl}_{\text {sat }}\right)$ electrode as a reference electrode. The working electrode was either an unmodified CNT paste electrode (CNTPE), $p$-aminophenol carbon paste electrode ( $p$-APMCPE), or a $p$-APMCNTPE. The prepared electrodes were characterized by scanning electron microscopy (SEM, XLC Philips). A pH meter (Corning, Model 140) with a double junction glass electrode was used to check the $\mathrm{pH}$ levels of the solutions.

\subsection{Preparation of the electrode}

To remove residual metals in the MWCNTs, $1.00 \mathrm{~g}$ of MWCNTs plus $20 \mathrm{~mL}$ of $\mathrm{HNO}_{3}$ (3.0 mol/L) were placed in a 25 $\mathrm{mL}$ flask and refluxed for $15 \mathrm{~h}$. Then, the MWCNTs were washed with water, centrifuged (3500 r/min) and dried at room temperature. $p$-Aminophenol $(1.0 \mathrm{mg})$ was handmixed with $89 \mathrm{mg}$ of graphite powder and $10 \mathrm{mg}$ of multiwall tubes in a mortar and pestle. Using a syringe, $880 \mathrm{mg}$ of paraffin oil was added to the mixture and mixed well for 40 min until a uniformly wetted paste was obtained. The paste was then packed into a glass tube. A $\mathrm{Cu}$ wire was push down the glass tube into the back of the mixture to make electrical contact. When necessary, a new surface was obtained by pushing an excess of the paste out of the tube and polishing with weighing paper. The unmodified CPE was prepared in the same way without adding $p$-aminophenol and CNTs to the mixture for use for comparison purposes. Unmodified CNTPE was also prepared in the same way using $90 \mathrm{mg}$ of graphite powder and $10 \mathrm{mg}$ of MWCNs and $880 \mathrm{mg}$ of paraffin oil. $p$-APMCPE was prepared as described above using $1.0 \mathrm{mg}$ of $p$-aminophenol, $99 \mathrm{mg}$ of graphite powder, and $880 \mathrm{mg}$ of paraffin oil.

\subsection{Preparation of water samples}

Before the sampling of the water, the polyethylene bottles were cleaned with concentrated $\mathrm{HNO}_{3}$, conditioned over $1 \mathrm{~d}$ with 1:100 (v/v) dilution of $\mathrm{HCl}(12 \mathrm{~mol} / \mathrm{L})$, and finally rinsed with water. Tap water and well water were sampled from our laboratory, and river water was obtained from the Zayandeh-Roud River (Isfahan, Iran). Water samples were stored in a refrigerator immediately after collection. Tap and well water samples were analyzed without any pre-treatment of the sample. For the river water, $10 \mathrm{~mL}$ of the sample was centrifuged for $10 \mathrm{~min}$ at $2000 \mathrm{r} / \mathrm{min}$ prior to analysis. Then, the 
samples were diluted twice with PBS ( $\mathrm{pH}$ 7.0). The sample solution was transferred into the voltammetric cell, and the HX and phenol contents were measured with the recommended procedure using the standard method.

\subsection{Recommended procedure}

The modified-MWCNT paste electrode was polished with clean filter paper. To prepare a blank solution, $10.0 \mathrm{~mL}$ of the buffer solution (PBS, pH 7.0) was transferred into an electrochemical cell. The initial and final potentials were adjusted to -0.20 and $+1.30 \mathrm{~V}$ versus $\mathrm{Ag} / \mathrm{AgCl}$, respectively. SWV was recorded with an amplitude potential of $50 \mathrm{mV}$ and frequency of $15 \mathrm{~Hz}$ to give the blank signal and the current labelled as $I_{\mathrm{pb}}$. Then, different amounts of HX and/or phenol were added to the cell using a micropipette. The square wave voltammogram was recorded again (similar to the above procedure) to get the analytical signals $\left(I_{\mathrm{ps}}\right)$. Calibration curves were constructed by plotting the net catalytic current peaks versus HX and/or phenol concentrations.

\section{Results and discussion}

\subsection{SEM characterization of the MWCNTS}

The structure of $p$-APMCNTPE was examined using a SEM. Figure 1(a) shows the presence of $p$-aminophenol in the electrode matrixes, a graphite layer, and MWCNTs. No mediator particles could be seen on the unmodified CNTPE, as shown in Fig. 1(b).

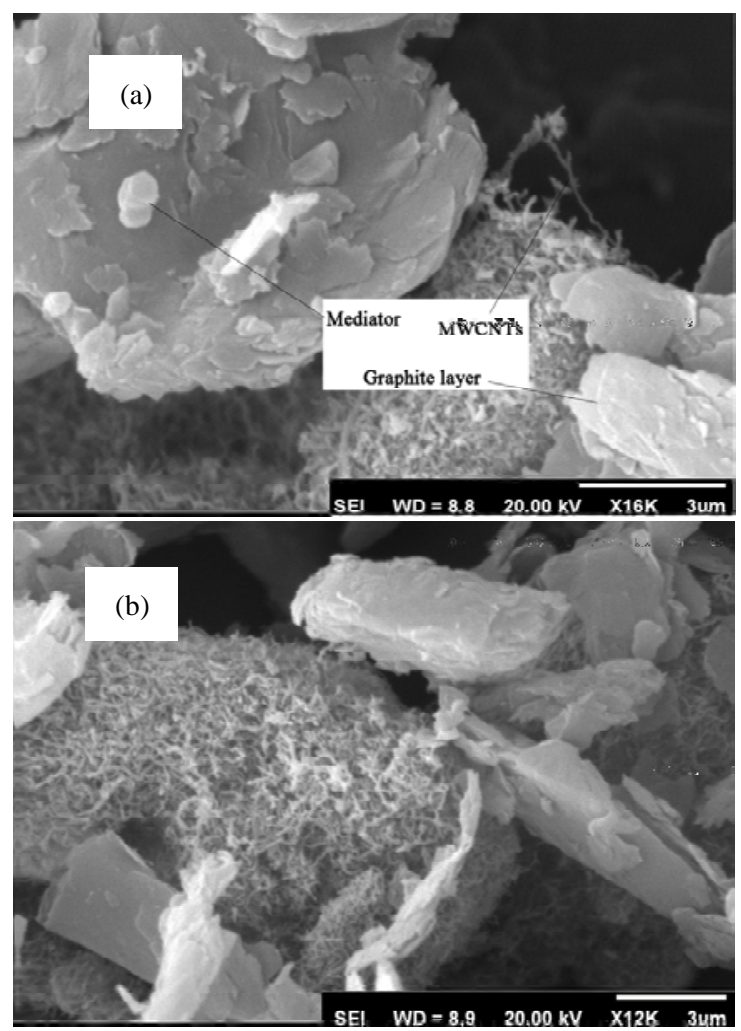

Fig. 1. SEM images of $p$-APMCNTPE (a) and unmodified CNTPE (b).

\subsection{Electrochemical behavior of p-APMCNTPE}

We have recently constructed a $p$-APMCNTPE by the incorporation of $p$-aminophenol into a MWCNT paste matrix, and we studied its electrochemical properties in buffered aqueous solution by CV [33]. The cyclic voltammogram exhibited an anodic peak $\left(E_{\mathrm{pa}}=0.175 \mathrm{~V}\right)$ and corresponding cathodic peaks with $E_{\mathrm{pc}}=0.050 \mathrm{~V}$ versus $\mathrm{Ag}|\mathrm{AgCl}| \mathrm{KCl}_{\mathrm{sat}}$, which were related to a quasi-reversible behavior of the $p-\mathrm{AP}_{(\mathrm{Red})} / p-\mathrm{AP}_{(0 \mathrm{x})}$ redox couple [33]. In addition, the result showed that the $p-\mathrm{AP}_{(\mathrm{Red})} / p-\mathrm{AP}_{(\mathrm{Ox})}$ redox is dependent on the $\mathrm{pH}$ of the aqueous solution.

\subsection{Catalytic effect}

In order to test the electrocatalytic activity of the $p$-APMCNTPE, its cyclic voltammetric responses at $10 \mathrm{mV} / \mathrm{s}$ were obtained at $\mathrm{pH} 7.0$ (phosphate buffer) in the absence and presence of HX $(800 \mu \mathrm{mol} / \mathrm{L})$. The results are presented in Fig. 2. It shows that in the absence of HX, a pair of well-defined redox peaks of $p$-APMCNTPE were observed. Upon the addition of HX, there was a drastic enhancement of the anodic peak current, and no cathodic current was observed in the reverse scan (curve (3)). The catalytic potential peak was at $200 \mathrm{mV}$. This behavior is consistent with a very strong electrocatalytic effect. Under the same experimental conditions, the direct oxidation of HX at the surface of unmodified CNTPE showed an irreversible wave at more positive potentials (curve (4)). The potential peak was at $960 \mathrm{mV}$, while that of the catalytic peak was at 200 $\mathrm{mV}$. Thus, a decrease in the overvoltage of approximately 760 $\mathrm{mV}$ and an enhancement of the peak current were achieved with the modified electrode. Under similar conditions, at a surface of $p$-APMCPE (curve (2)) and CPE (curve (5)), HX gave a lower current than those from $p$-APMCNTPE and CNTPE with high conductivity MWCNTs in the electrode matrix. The cyclic voltammogram for CNTPE in phosphate buffer $(0.1 \mathrm{~mol} / \mathrm{L}, \mathrm{pH}$ 7.0) without HX is shown in Fig. 2 (curve (6)). It showed that there was no oxidation nor reduction signal with the CNTPE at the applied potential range in the absence of $\mathrm{HX}$ and p-aminophenol.

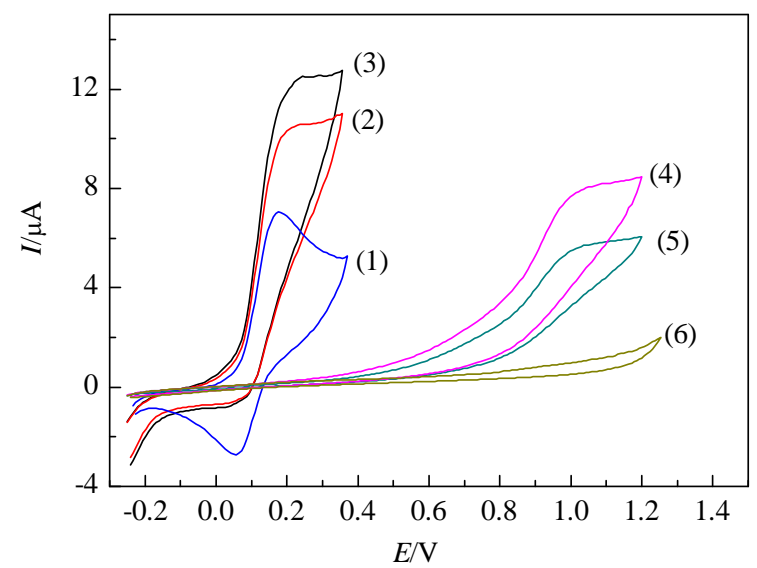

Fig. 2. Cyclic voltammograms of $p$-APMCNTPE. (1) $0.1 \mathrm{~mol} / \mathrm{L} \mathrm{PBS}(\mathrm{pH}$ 7.0) at $p$-APMCNTPE; (2) $0.1 \mathrm{~mol} / \mathrm{L}$ PBS in the presence of $800 \mu \mathrm{mol} / \mathrm{L}$ $\mathrm{HX}$ at $p$-APMCPE; (3) As (2) at $p$-APMCNTPE; (4) As (3) at CNTPE; (5) As (2) at CPE; (6) As (1) at CNTPE. Scan rate $=20 \mathrm{mV} / \mathrm{s}$. 


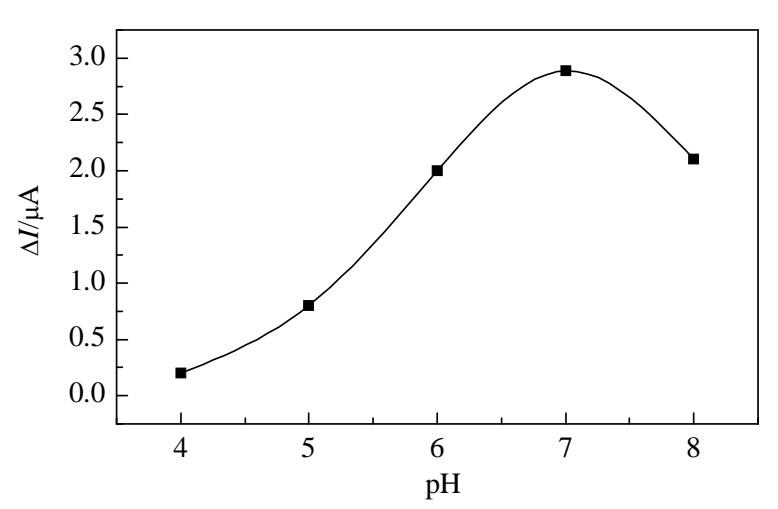

Fig. 3. Net current versus $\mathrm{pH}$ for the electro-oxidation of $600 \mu \mathrm{mol} / \mathrm{L}$ $\mathrm{HX}$ at $p$-APMCNTPE with a scan rate of $10 \mathrm{mV} / \mathrm{s}$.

The electrochemical behavior of $p$-APMCNTPE in the oxidation of HX is dependent on the $\mathrm{pH}$ of the solution. By increasing the solution $\mathrm{pH}$, the potential peak of the electrocatalyst ( $p$-aminophenol) was shifted to more positive values. Thus, the thermodynamic driving force for the catalytic activity varied with $\mathrm{pH}$, which caused the current peaks and shapes of the cyclic voltammogram to change at different $\mathrm{pH}$ values. Figure 3 shows the change in the peak current $(\Delta I)$ versus $\mathrm{pH}$. The optimum $\mathrm{pH}$ for the electrocatalytic oxidation of $\mathrm{HX}$ at $p$-aminophenol is $\mathrm{pH}$ 7.0. Therefore, $\mathrm{pH} 7.0$ was selected as the optimum $\mathrm{pH}$ for the electrocatalysis detection of HX at the surface of $p$-APMCNTPE. Hence, all electrochemical experiments were done at this $\mathrm{pH}$ value.

Figure 4 shows cyclic voltammograms of HX, phenol, and their mixture at the surface of CNTPE. As can be seen, the potential peaks for these compounds overlapped. Therefore, the determination of the concentrations of the individual compounds at the surface of the unmodified CNTPE was impossible (curve (3)). On the other hand, at the surface of the modified-CPE ( $p$-APMCPE), we observed two separated potential peaks corresponding to HX and phenol (curve (4)). In addition, as shown in Fig. 2, p-APMCNTPE clearly showed a higher electrocatalytic activity towards HX.

Figure 5(a) shows the voltammetric curves of $p$-APMCNTPE

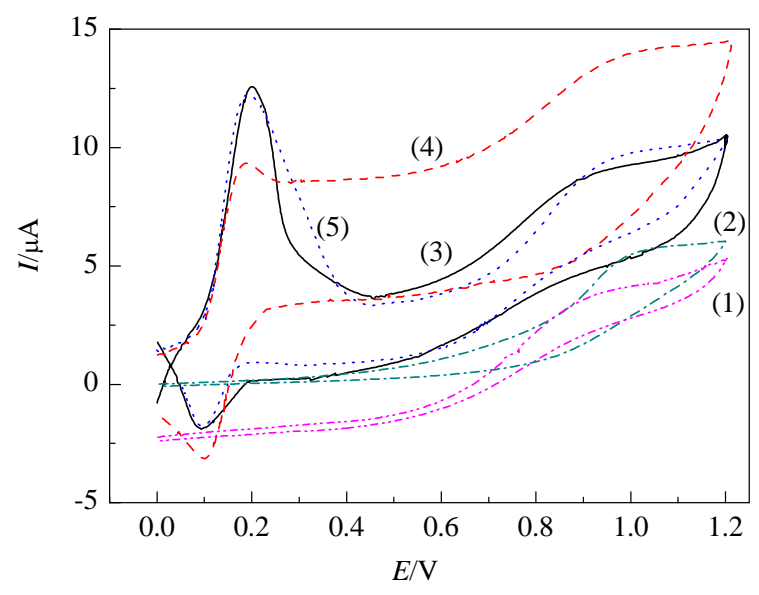

Fig. 4. Cyclic voltammograms of the samples. (1) $450 \mu \mathrm{mol} / \mathrm{L} \mathrm{HX}$ at CNTPE; (2) $400 \mu \mathrm{mol} / \mathrm{L}$ phenol at CNTPE; (3) $450 \mu \mathrm{mol} / \mathrm{L} \mathrm{HX}$ at $p$-APMCNTPE; (4) $400 \mu \mathrm{mol} / \mathrm{L}$ phenol at $p$-APMCNTPE; (5) $400 \mu \mathrm{mol} / \mathrm{L}$ phenol and $450 \mu \mathrm{mol} / \mathrm{L} \mathrm{HX}$ at $p$-APMCNTPE. Conditions: $0.1 \mathrm{~mol} / \mathrm{L}$ phosphate solution ( $\mathrm{pH} 7.0)$.

at scan rates ranging from 1 to $20 \mathrm{mV} / \mathrm{s}$ at $\mathrm{pH} 7.0$ in a solution containing HX $(800 \mu \mathrm{mol} / \mathrm{L})$. We observed a linear correlation of the peak current with the square root of the scan rate $\left(v^{1 / 2}\right)$ (Fig. 5(b)).The result clearly indicated a diffusion-controlled electro-oxidation process. The plot of the current (Fig. 5(c)) gave the characteristic shape due to a coupled chemical reaction ( $\mathrm{EC}_{\mathrm{cat}}$ ) for $\mathrm{HX}$, clearly confirming the electrocatalytic behavior of the mediator. On this basis, we suggested an electrocatalytic mechanism (Scheme 1) for the oxidation of HX.

Figure 6(a) shows the cyclic voltammograms of p-APMCNTPE in phosphate buffer $(0.1 \mathrm{~mol} / \mathrm{L}, \mathrm{pH} 7.0)$ containing $\mathrm{HX}(600 \mu \mathrm{mol} / \mathrm{L})$ at sweep rates of 8,14 , and $25 \mathrm{mV} / \mathrm{s}$. The points show the rising part of the voltammograms, which is the Tafel region. This region is affected by electron transfer kinetics between HX and a $p$-APMCNTPE, assuming that the deprotonation of HX is a sufficiently fast step. To evaluatethe kinetic parameters, the Tafel plots were drawn (Fig. 6(b)) using the points of the Tafel region of the cyclic voltammograms in the inset. The results of polarization studies for electrooxidation of
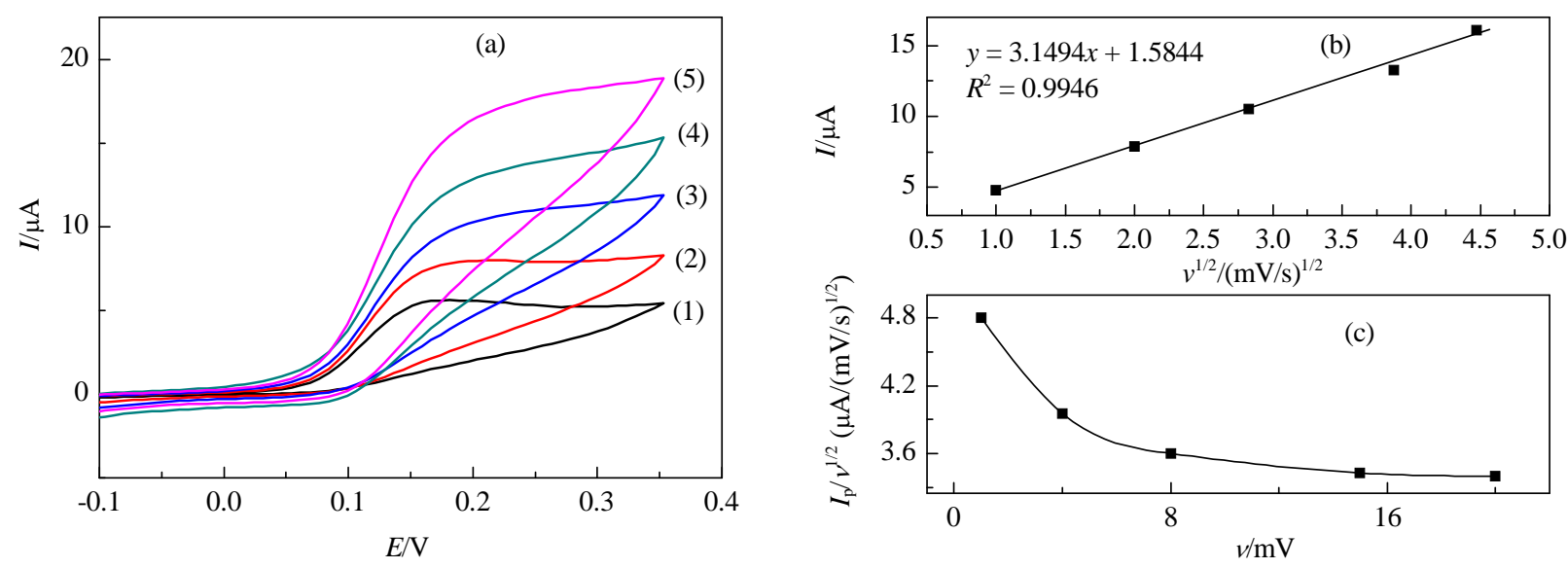

Fig. 5. (a) Cyclic voltammograms of $800 \mu \mathrm{mol} / \mathrm{L} \mathrm{HX}$ at various scan rates of 1.0 (1), 4.0 (2), 8.0 (3), 15.0 (4), $20 \mathrm{mV} / \mathrm{s}$ (5) in $0.1 \mathrm{~mol} / \mathrm{L} \mathrm{PBS} \mathrm{(pH} \mathrm{7.0);}$ (b) Plot of $I_{\mathrm{pa}}$ versus $v^{1 / 2}$ for the oxidation of HX at $p$-APMCNTPE; (c) Scan rate-normalized current $\left(I_{\mathrm{p}} / v^{1 / 2}\right)$ versus scan rate. 


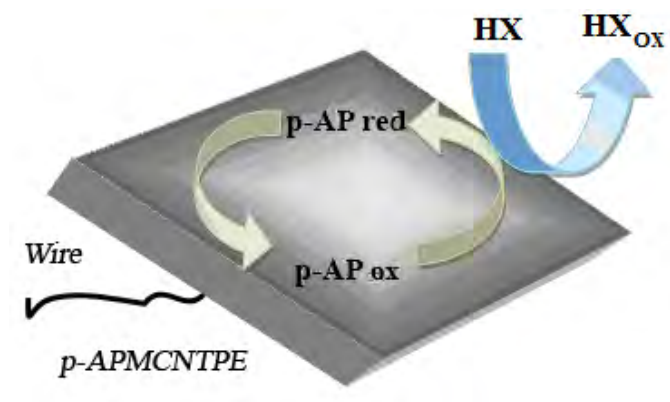

Scheme 1. Electrocatalysis by $p$-aminophenol in the oxidation of HX.

HX at $p$-APMCNTPE showed that the average Tafel slope was $9.8765 \mathrm{~V}^{-1}$. Using the Tafel equation $(n(1-\alpha) F / 2.3 R T)$, we obtained the charge transfer coefficient $\alpha=0.42$.

\subsection{Chronoamperometric studies}

Figure 7(a) shows the chronoamperomegrams recorded at different concentrations of HX by setting the potential of the working electrode at 100 and $250 \mathrm{mV}$. For an electroactive reagent with a diffusion coefficient of $D$ (HX in this case), the current for the electrochemical reaction with a mass transport limited rate is described by the Cottrell equation [34]. Under diffusion control, a plot of $I$ versus $t^{-1 / 2}$ is linear, and the value of $D$ can be obtained from the slope. Figure 7(b) shows the experimental plots together with the best fits for the different HX concentrations employed. The slopes of the resulting straight lines were plotted versus HX concentration. The value of $D$ was found to be $5.56 \times 10^{-5} \mathrm{~cm}^{2} / \mathrm{s}$, which was in agreement with the value reported in the literature [35].

Kinetic studies by chronoamperometry confirmed the electron transfer rates in the presence and absence of HX. At an intermediate time, the catalytic current $\left(I_{C}\right)$ is dominated by the rate of electrocatalyzed oxidation of HX. Therefore, the rate constant for the reaction between $\mathrm{HX}$ and the electrocatalyst was determined using the method described in the literature [34]:

$$
I_{\mathrm{C}} / I_{\mathrm{L}}=\pi^{1 / 2} \gamma^{1 / 2}=\pi^{1 / 2}\left(k C_{\mathrm{b}} t\right)^{1 / 2}
$$

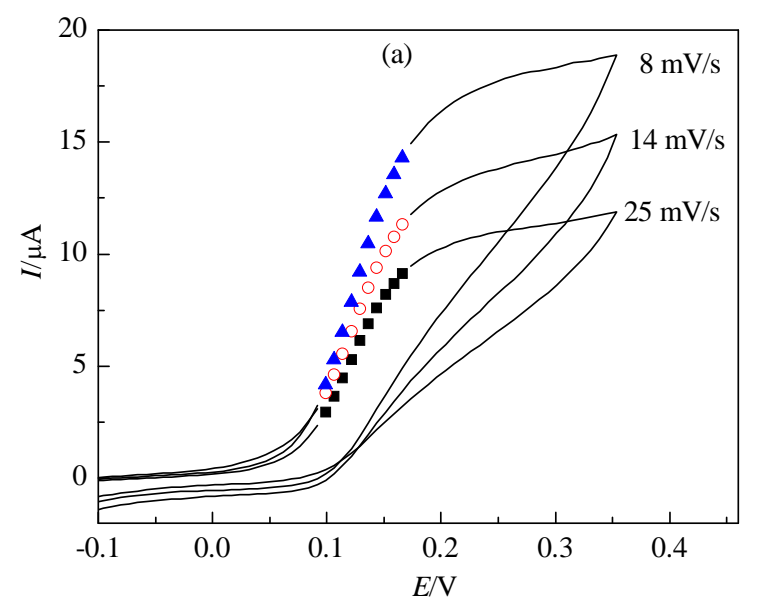

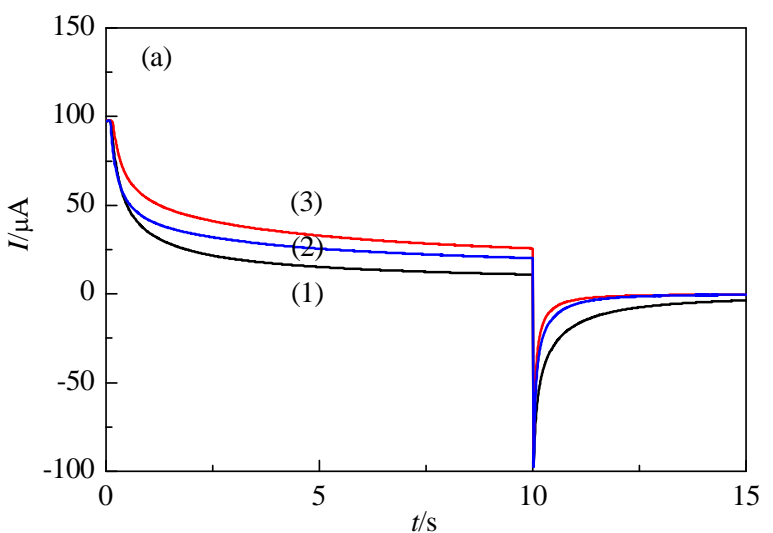
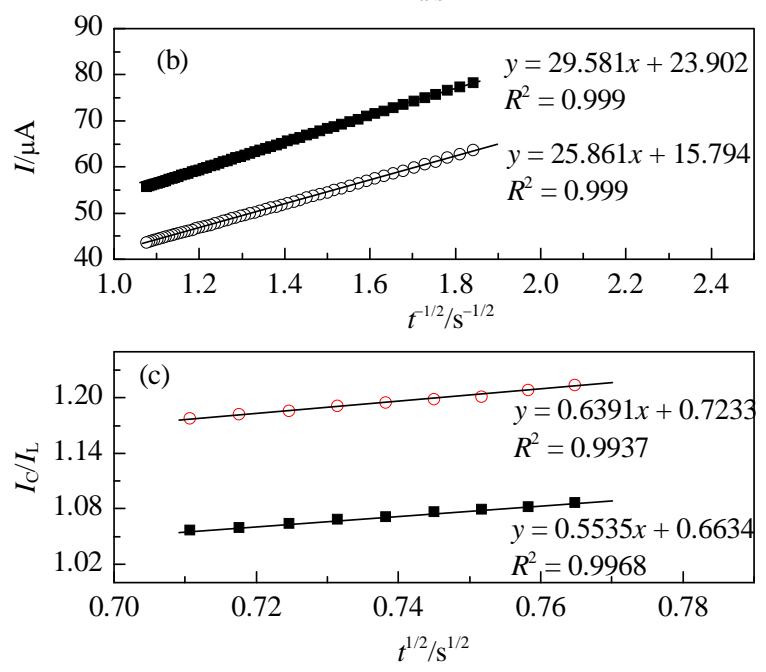

Fig. 7. (a) Chronoamperograms obtained at $p$-APMCNTPE in the absence (1) and in the presence of 300 (2) and 500 (3) $\mu \mathrm{mol} / \mathrm{L} \mathrm{HX}$ at pH 7.0; (b) Cottrell plots for the data from the chronoamperograms; (c) Dependence of $I_{\mathrm{C}} / I_{\mathrm{L}}$ on the $t^{1 / 2}$ derived from the chronoamperogram data.

where $I_{\mathrm{C}}$ is the catalytic current, $I_{\mathrm{L}}$ is the limited current in the absence of HX, and $C_{b}$ is the bulk concentration of HX. Eq. (1) can be used to calculate the rate constant of the catalytic process. Based on the slope of the $I_{\mathrm{C}} / I_{\mathrm{L}}$ versus $t^{1 / 2}$ plot, $k$ was obtained for a given HX concentration. These plots obtained from

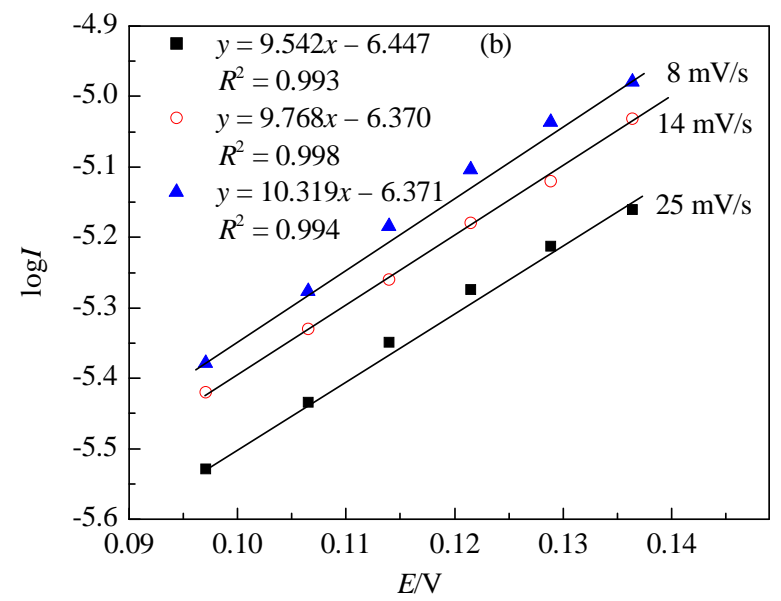

Fig. 6. (a) Cyclic voltammograms (at 8, 14, and $25 \mathrm{mV} / \mathrm{s}$ ) of a $p$-APMCNTPE in phosphate buffer (0.1 mol/L, pH 7.0). (b) Tafel plots for $p$-APMCNTPE in $0.1 \mathrm{~mol} / \mathrm{L}$ PBS (pH 7.0) with scan rates of 8, 14, and $25 \mathrm{mV} / \mathrm{s}$ in the presence of $600 \mu \mathrm{mol} / \mathrm{L} \mathrm{HX}$. 
the chronoamperograms are shown in Fig. 7(c). From the values of the slopes, $k$ was found to be $2.92 \times 10^{2} \mathrm{~mol}^{-1} \mathrm{~L} \mathrm{~s}^{-1}$. The value of $k$ explains the sharp feature of the catalytic peak potential for the oxidation of HX at the surface of $p$-APMCNTPE.

\subsection{EIS study}

EIS can also provide information about impedance changes on the electrode surface and its electron transfer ability during the electrocatalytic process. A typical Nyquist plot for this system consists of a semicircle portion observed at the higher frequency range corresponding to the electron transfer-limited process and a linear part at lower frequencies representing the diffusion limited process (see Fig. 8). The EIS data were fitted using the FRA 4.9 software and a complex nonlinear least square (CNLS) approximation method, from which the electron transfer kinetics as charge transfer resistance $\left(R_{\mathrm{ct}}\right)$, solution resistance $\left(R_{\mathrm{s}}\right)$, double-layer capacitance $\left(C_{\mathrm{dl}}\right)$ and constant phase element (CPE) and mass transfer element $W$ (Warburg impedance) were extracted. The EIS data obtained at the $p$-APMCNTPE was fitted to the Randles circuit $R_{\mathrm{s}}\left(C_{\mathrm{dl}}\left[R_{\mathrm{ct}} W\right]\right)$. Figure 8 compares the Nyquist diagram plot of the electrodes recorded in PBS (pH 7.0) without phenol and HX and with phenol $(500 \mu \mathrm{mol} / \mathrm{L})$ and $\mathrm{HX}(500 \mu \mathrm{mol} / \mathrm{L})$. The charge transfer resistance for $\mathrm{HX}$ at the modified electrode was significantly lower than that of the resistance for phenol under the same conditions. This means that HX was catalyzed by $p$-aminophenol at the surface of the electrode, but phenol was not catalysed under the same condition.

\subsection{Stability and reproducibility}

The repeatability and stability of $p$-APMCNTPE was investigated using SWV measurements of 1.0 and $5.0 \mu \mathrm{mol} / \mathrm{L}$ of $\mathrm{HX}$ and 15.0 and $30.0 \mu \mathrm{mol} / \mathrm{L}$ of phenol. The relative standard deviations (RSD) for seven successive assays were $1.3 \%, 1.5 \%$, and $1.1 \%, 1.2 \%$, respectively. When we used five different electrodes, the RSD for four measurements was $2.8 \%$. When the electrode was stored in our laboratory at room temperature, the modified electrode retained $97 \%$ of its initial response after a week and $93 \%$ after $35 \mathrm{~d}$. These results indicated that $p$-APMCNTPE has good stability and reproducibility and can be used for the detection of HX and phenol.

\subsection{Calibration plot and limit of detection}

SWV (with amplitude potential of $50 \mathrm{mV}$ and frequency of

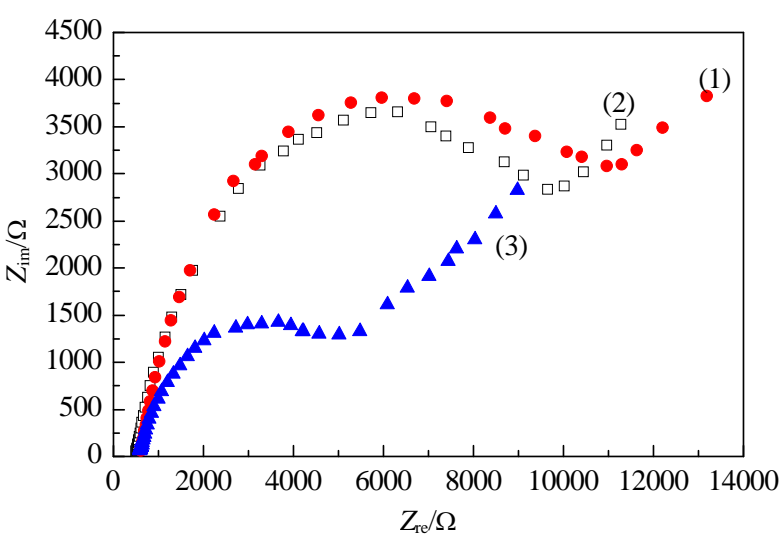

Fig. 8. Nyquist diagrams of $p$-APMCNTPE in the absence (1) and in the presence of $500 \mu \mathrm{mol} / \mathrm{L} \mathrm{HX} \mathrm{(2)} \mathrm{and} \mathrm{phenol} \mathrm{(3)} \mathrm{at} \mathrm{pH} 7.0$, respectively. Bias is $0.15 \mathrm{~V}$ with $E_{\mathrm{ac}}=5 \mathrm{mV}$ with a frequency range of $10 \mathrm{kHz}$ to $1 \mathrm{~Hz}$.

$15 \mathrm{~Hz}$ ) was used to determine the concentrations of HX and phenol because it is sensitive and fast. The SW voltammograms clearly showed that the peak current versus HX concentration was linear in the range of 0.5 to $180.0 \mu \mathrm{mol} / \mathrm{L}$ of HX. The regression equation was $\Delta I_{\mathrm{p}}(\mu \mathrm{A})=(0.136 \pm 0.034) C_{\mathrm{HX}}+$ (2.006 \pm 0.3110$)\left(R^{2}=0.990, n=10\right)$. The regression equation for phenolin in the range of 10.0 to $650 \mu \mathrm{mol} / \mathrm{L}$ was $\Delta I_{\mathrm{p}}(\mu \mathrm{A})=$ $(0.0582 \pm 0.0045) C_{\text {Phenol }}+(1.3829 \pm 0.0567)\left(R^{2}=0.9937, n=9\right)$, where $C$ is concentration of $\mathrm{HX}(\mu \mathrm{mol} / \mathrm{L})$ and/or phenol and $\Delta I_{\mathrm{p}}$ is the net peak current.

The detection limits were determined to be $0.15 \mu \mathrm{mol} / \mathrm{L} \mathrm{HX}$ and $7.1 \mu \mathrm{mol} / \mathrm{L}$ phenol using the definition of $Y_{\mathrm{LOD}}=Y_{\mathrm{B}}+3 \mathrm{~s}$. The detection limit, linear dynamic range, and sensitivity for $\mathrm{HX}$ were comparable or better than those of several other modified electrodes (Table 1).

The main object of this study was to detect HX and phenol simultaneously. This was performed by simultaneously changing the concentrations of HX and phenol and recording the SWVs. The results showed well-defined anodic peaks at the potentials of 150 and $800 \mathrm{mV}$, corresponding to the oxidation of HX and phenol, respectively. These results indicated that the simultaneous determination of these compounds is feasible with $p$-APMCNTPE (Fig. 9). The sensitivity of the determination of the oxidation of $\mathrm{HX}$ was found to be $0.1361 \pm 0.0340$ $\mu \mathrm{A}(\mu \mathrm{mol} / \mathrm{L})^{-1}$. This was very close to the value obtained in the presence of phenol, which was $0.1349 \pm 0.0563 \mu \mathrm{A}(\mu \mathrm{mol} / \mathrm{L})^{-1}$ (see Fig. 9), indicating that the oxidation processes of these compounds at $p$-APMCNTPE were independent, and therefore, the simultaneous determination of their mixtures is possible without interferences.

Table 1

Comparison of the efficiency of some electrochemical methods for the determination of HX.

\begin{tabular}{lccccc}
\hline Method & Used catalyst & LDR $(\mu \mathrm{mol} / \mathrm{L})$ & LOD $(\mu \mathrm{mol} / \mathrm{L})$ & $\mathrm{pH}$ & \multicolumn{1}{c}{ Ref. } \\
\hline Amperometry & HCCHCFa & $4.6-1800$ & 0.21 & 7.0 & 7 \\
DPV b & Quinizarine & $1.0-400$ & 0.17 & 7.0 & 35 \\
Amperometry & Rutin & $1.0-81.7$ & 1.00 & 8.0 & 36 \\
DPV & Coumestan & $60-1000$ & 10.75 & 7.0 & 37 \\
DPV & Magnetic microspheres & $0.07-31.25$ & 0.03 & 4.5 & 10 \\
SWV & p-Aminophenol & $0.5-180$ & 0.15 & 7.0 & this work \\
\hline
\end{tabular}

${ }^{a}$ Hybrid copper-cobalt hexacyanophrate.

${ }^{\mathrm{b}}$ Differential pulse voltammetry. 

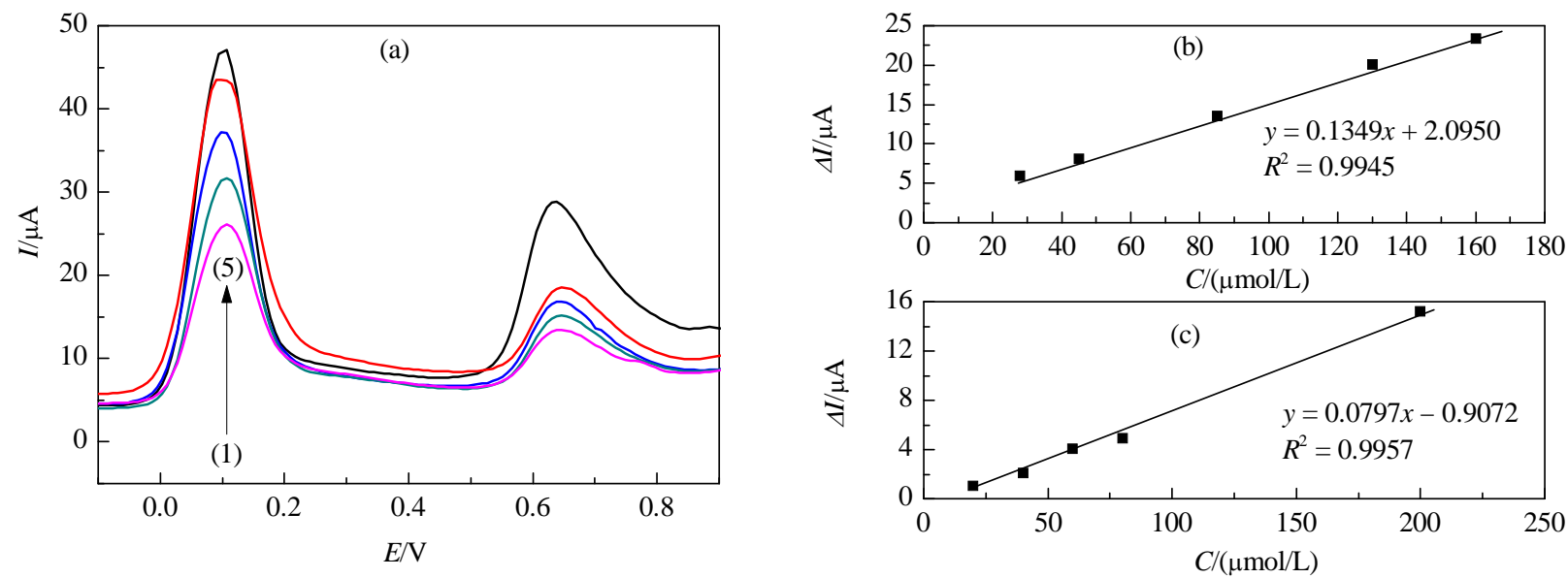

Fig. 9. (a) Square wave voltammograms of $p$-APMCNTPE in $0.1 \mathrm{~mol} / \mathrm{L}$ PBS containing different concentrations of HX and phenol mixed solutions of $28.0+20.0$ (1), 45.0+40.0 (2), 85.0+60.0 (3), 130.0+80.0 (4), and 160.0+200.0 $\mu \mathrm{mol} / \mathrm{L}$ (5); (b) Plot of the peak currents as a function of HX concentration; (c) Plot of the peak currents as a function of phenol concentration.

\subsection{Interference studies}

Various substances as potential interfering compounds of the determination of HX and phenol were studied under the optimum conditions with 1.0 and $15.0 \mu \mathrm{mol} / \mathrm{L}$ phenol at $\mathrm{pH}$ 7.0. The interfering substances were chosen from the group of substances commonly found with these compounds in real samples. The tolerance limit was defined as the maximum concentration of the interfering substance that caused an error of less than $\pm 5 \%$ in the determination of $\mathrm{HX}$ and phenol. In the experiments, we found that neither 1000 fold of $\mathrm{Ca}^{2+}, \mathrm{Mg}^{2+}, \mathrm{SO}_{4}{ }^{2-}$, $\mathrm{Al}^{3+}, \mathrm{NH}_{4}^{+}, \mathrm{F}^{-}, \mathrm{Li}^{+}, \mathrm{Ba}^{2+}, \mathrm{C}_{2} \mathrm{O}_{4}{ }^{2-}, \mathrm{NO}_{3}^{-}, \mathrm{CH}_{3} \mathrm{COO}^{-}$, and $\mathrm{ClO}_{4}^{-}$, nor 600 fold of gallic acid, ellagic acid, citrate, EDTA, glucose, fructose, sucrose, lactose, and chrysin, nor 5 fold of hydrazine interfered with the determination of HX and phenol. Hydrazine is very similar to HX in structure, and it usually interferes with HX analysis in real samples [11].

In a second type of experiment, a calibration plot was obtained with the coexistence of the interfering compound and $\mathrm{HX}$ at the same concentration. However, none of the substances chosen for selectivity study $\left(\mathrm{Ca}^{2+}, \mathrm{Mg}^{2+}, \mathrm{SO}_{4}{ }^{2-}, \mathrm{Al}^{3+}, \mathrm{NH}_{4}{ }^{+}, \mathrm{F}^{-}, \mathrm{Li}^{+}\right.$, $\mathrm{Ba}^{2+}, \mathrm{C}_{2} \mathrm{O}_{4}^{2-}, \mathrm{NO}_{3}{ }^{-}, \mathrm{CH}_{3} \mathrm{COO}^{-}, \mathrm{ClO}_{4}^{-}$, gallic acid, ellagic acid, citrate, EDTA, glucose, fructose, sucrose, lactose and chrysin) showed an interference effect on HX and phenol. The dynamic ranges and sensitivities in the absence of the potential interfering substance were very close to the value obtained with the coexistence of these substances and HX and phenol. However, the interference of hydrazine was not negligible when the concentrations of hydrazine and HX were higher than $40.0 \mu \mathrm{mol} / \mathrm{L}$. The HX sensitivities were calculated to be $0.1361 \pm 0.0340$ and $0.1168 \pm 0.0426 \mu \mathrm{A}(\mu \mathrm{mol} / \mathrm{L})^{-1}$, respectively, in the absence of hydrazine and with the coexistence of hydrazine and HX. This can be attributed to the similarity in the structure of HX and hydrazine. On the other hand, the $p$-APMCNTPE can easily discriminate $\mathrm{HX}$ from hydrazine at low concentration levels (from 0.5 to $40.0 \mu \mathrm{mol} / \mathrm{L})$.

\subsection{Real sample analysis}

To evaluate the applicability of the proposed method to real sample analysis, it was applied to the determination of HX and phenol in water samples. The samples tested were found to be free from HX and phenol. Thus, synthetic samples were prepared by adding known amounts of HX and phenol to the water samples. The results are given in Table 2 .

\section{Conclusions}

A carbon paste electrodechemically modified by the incorporation of MWCNTs as a sensor and $p$-aminophenol as modifier was prepared for the determination of $\mathrm{HX}$ and phenol in the presence of one another. The electrochemical behavior of $p$-APMCNTPE was studied by $\mathrm{CV}$ and shown to be a suitable sensor for the simultaneous determination of HX and phenol.

Table 2

Determination of HX and phenol in water samples.

\begin{tabular}{lcccccc}
\hline Sample & $\begin{array}{c}\text { HX added } \\
(\mu \mathrm{mol} / \mathrm{L})\end{array}$ & $\begin{array}{c}\text { HX found } \\
(\mu \mathrm{mol} / \mathrm{L})\end{array}$ & $\begin{array}{c}\text { Standard method [7] } \\
(\mu \mathrm{mol} / \mathrm{L})\end{array}$ & $\begin{array}{c}\text { Phenol added } \\
(\mu \mathrm{mol} / \mathrm{L})\end{array}$ & $\begin{array}{c}\text { Phenol found } \\
(\mu \mathrm{mol} / \mathrm{L})\end{array}$ & $\begin{array}{c}\text { Standard method [38] } \\
(\mu \mathrm{mol} / \mathrm{L})\end{array}$ \\
\hline Tap Water & - & $<$ Limit of detection & - & - & - & $<$ Limit of detection \\
& 1.0 & $1.05 \pm 0.08$ & $1.2 \pm 0.21$ & 15.0 & $15.24 \pm 0.12$ & $15.41 \pm 0.97$ \\
& 10.0 & $10.51 \pm 0.93$ & $10.91 \pm 1.05$ & 30.0 & $30.64 \pm 0.75$ & $30.95 \pm 1.10$ \\
Well Water & - & $<$ Limit of detection & - & - & $<$ Limit of detection & - \\
& 5.0 & $5.3 \pm 0.41$ & $5.8 \pm 1.10$ & 20.0 & $20.11 \pm 0.55$ & $21.24 \pm 1.05$ \\
River Water & 50.0 & $51.04 \pm 1.15$ & $51.64 \pm 1.75$ & 80.0 & $80.55 \pm 0.65$ & $80.95 \pm 1.12$ \\
& - & $<$ Limit of detection & - & - & $<$ Limit of detection & - \\
& 20.0 & $20.35 \pm 0.42$ & $20.85 \pm 0.92$ & 100.0 & $101 \pm 1.3$ & $101.8 \pm 1.9$ \\
\hline
\end{tabular}




\section{Graphical Abstract}

Chin. J. Catal., 2013, 34: 1768-1775 doi: 10.1016/S1872-2067(12)60652-4

\section{Simultaneous determination of hydroxylamine and phenol using $p$-aminophenol-modified carbon nanotube paste electrode}

Ali A. Ensafi*, E. Heydari-Bafrooei, B. Rezaei

Isfahan University of Technology, Iran

A carbon paste electrode chemically modified with multiwall carbon nanotubes and $p$-aminophenol was prepared and used as a selective electrochemical sensor for the simultaneous determination of hydroxylamine and phenol in water samples.

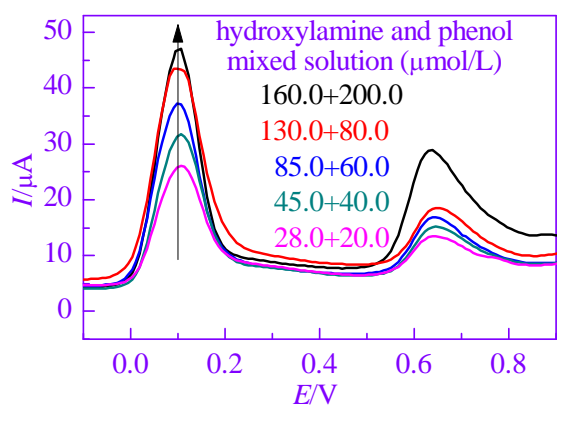

The potential peaks for HX and phenol were separated by 650 $\mathrm{mV}$, which is large enough to detect $\mathrm{HX}$ and phenol individually and simultaneously. The modified electrode was used for the determination of HX and phenol in real water samples.

\section{Acknowledgements}

The authors wish to thank the Research Council of Isfahan University of Technology (IUT), the Center of Excellence in Sensor and Green Chemistry, and the Iranian Nanotechnology Initiative Council for their support.

\section{References}

[1] Patnaik P. Handbook of Inorganic Chemicals. New York: McGraw Hill, 2003

[2] Miller F P, Vandome A F, McBrewster J. Hydroxylamine. Buchbeschreibung: VDM Publishing House Ltd, 2010

[3] Prokai A M, Ravichandran R K. J Chromatogr A, 1994, 667: 298

[4] Dias F, Olojola A S, Jaselskis B. Talanta, 1979, 26: 47

[5] Kavlentis E. Microchem J, 1988, 37: 22

[6] Afkhami A, Madrakian T, Maleki A. Anal Sci, 2006, 22: 329

[7] Cui X P, Hong L, Lin X Q. Anal Sci, 2002, 18: 543

[8] Ebadi M. Electrochim Acta, 2003, 48: 4233

[9] Mazloum-Ardakani M, Taleat Z. Int J Electrochem Sci, 2009, 4: 694

[10] Yang M, Zhu J J. Analyst, 2003, 128: 178

[11] Mazloum-Ardakani M, Karimi M A, Mirdehghan S M, Zare M M, Mazidi R. Sens Actuators B, 2008, 132: 52

[12] Li J, Lin X Q. Sens Actuators B, 2007, 126: 527

[13] Budavari S. The Merck Index: An Encyclopedia of Chemical, Drugs, and Biologicals. 12th Ed. Whitehouse Satation: Merck \& Co., 1996

[14] Lin T M, Lee S S, Lai C S, Lin S D. Burns, 2006, 32: 517

[15] Agency for Toxic Substances and Disease Registry. Toxicological Profile for Phenol. Atlanta: U.S. Department of Health and Human Services, Public Health Service, 2008

[16] Hansch C, McKarns S C, Smith C J, Doolittle D J. Chem Biol Interact, 2000, 127: 61
[17] Brega A, Prandini P, Amaglio C, Pafumi E. J Chromatogr A, 1990, 535: 311

[18] Wada M, Kinoshita S, Itayama Y, Kuroda N, Nakashima K. J Chromatogr B, 1999, 721: 179

[19] Makuch B, Gazda K, Kamiśnski M. Anal Chim Acta, 1993, 284: 53

[20] Bieniek G. J Chromatogr B, 1996, 682: 167

[21] Khalaf K D, Hasan B A, Morales-Rubio A, de la Guardia M. Talanta, 1994, 41: 547

[22] Notsu H, Tatsuma T, Fujishima A. J Electroanal Chem, 2002, 523: 86

[23] De Carvalho R M, Mello C, Kubota L T. Anal Chim Acta, 2000, 420: 109

[24] Schiller J G, Chen A K, Liu C C. Anal Biochem, 1978, 85: 25

[25] Iijima S. Nature, 1991, 354: 56

[26] Dresselhaus M S, Dresselhaus G, Eklund P C. Science of Fullerenes and Carbon Nanotubes. London: Academic Press, 1996

[27] Ebbesen T W. Carbon Nanotubes: Preparation and Properties. Boca Raton, FL: CRC Press, 1997

[28] Dillon A C, Jones K M, Bekkedahl T A, Kiang C H, Bethune D S, Heben M J. Nature, 1997, 386: 377

[29] Mordkovich V Z, Baxendale M, Chang R P H, Yoshimura S. Synth Met, 1997, 86: 2049

[30] Niu C M, Sichel E K, Hoch R, Moy D, Tennet H. Appl Phys Lett, 1997, 70: 1480

[31] Svancara I, Vytras K, Barek J, Zima J. Crit Rev Anal Chem, 2001, 31: 311

[32] Zima J, Svancara I, Barek J, Vytras K. Crit Rev Anal Chem, 2009, 39: 204

[33] Ensafi A A, Khoddami E, Rezaei B, Karimi-Maleh H. Colloids Surf B, 2010, 81: 42

[34] Bard A J, Faulkner L R. Electrochemical Methods. Fundamentals and Applications. New York: Wiley, 2001

[35] Mazloum-Ardakani M, Beitollahi H, Taleat Z, Naeimi H. Anal Methods, 2010, 2: 1764

[36] Zare H R, Sobhani Z, Mazloum-Ardakani M. Sens Actuatrs B, 2007, 126: 641

[37] Zare H R, Nasirizadeh N. Electroanalysis, 2006, 18: 507

[38] Lupu S, Ion I, Ion A C. Rev Roum Chim, 2009, 54: 351 